kinh cơ và siêu âm thần kinh giữa với đầy đủ các thông số. Tác giả Miedany năm 2004 khi nghiên cứu sự liên quan diện tích thần kinh giữa và điện sinh lý thần kinh cơ cũng có kết luận tương tự ${ }^{4}$.

Kết quả tương tự theo tác giả Min-Kyu Kim năm 2014 khi nghiên cứu 135 bệnh nhân từ năm 2007 đến 2009 tại 19 trung tâm y tế tại Hàn Quốc7.

\section{KẾT LUẬN}

Qua khảo sát trên 38 bệnh nhân với 42 bàn tay bệnh nhân mắc hội chứng OCT mức độ nặng và rất nặng, chúng tôi có kết luận như sau:

- Tăng hiệu thời gian tiềm vận động và hiệu thời gian tiềm cảm giác giữa TK giữa và TK trụ, lần lượt là $5,19 \pm 3,83 \mathrm{~ms}$ và $3,11 \pm 2,2 \mathrm{~ms}$.

- Tăng diện tích TK giữa đoạn ngang OCT, trung bình là 14,48 $\pm 6,27 \mathrm{~mm}^{2}$.

\section{TÀI LIÊU THAM KHẢO}

1. Jimenez DF, Gibbs SR, Clapper AT. Endoscopic treatment of carpal tunnel syndrome: a critical review. Neurosurg Focus e6. 1997.

2. Nguyễn Lê Trung Hiếu. Vũ Anh Nhi. Phân đô lâm sàng và điện sinh lý thần kinh cớ trong hội chứng ông cổ tay. Y học TP Hồ Chí Minh, 9. 2008.

3. Nguyễn Lê Trung Hiếu. Khảo sát điện sinh lí thẩn kinh cơ và lâm sàng trong hội chứng ông cổ tay. 2002;32-34.

4. EI Miedany. Aty S A. Ultrasonography versus nerve conduction study in patients with carpal tunnel syndrome: substantive or complementary test? Rheumatology (Oxford), 2004;43(7): 887-895.

5. Wilgis Efs. Burke Fd. Dubin Nh. A prospective assessment of carpal tunnel surgery with respect to age. Hand Surg, 2006;31B: 401- 406.

6. Đoàn Việt Trình. Đăc điểm hình ảnh và vai trò của siêu ẩm trong chẩn đoán và theo dõi kết quả sau phẫu thuật điều trị hội chứng ống cổ tay tại bệnh viện trường đại học $Y$ Hà Nội từ tháng 11/2013 đến tháng 09/2014, Luận văn thạc sỹ y học, Đai học Y Hà Nội, 2014;8-30.

7. M. K. Kim, et al. Value of ultrasonography in the diagnosis of carpal tunnel syndrome: correlation with electrophysiological abnormalities and clinical severity. J Korean Neurosurg Soc, 2014;55(2): 78-82.

\title{
ĐẶC ĐIỂM LÂM SÀNG HÀNH VI Tự SÁT Ở BỆNH NHÂN TÂM THẦN PHÂN LIỆT
}

\section{TÓM TẮT}

Mục tiêu: Mô tả đặc điểm lâm sàng hành vi tự sát ở bệnh nhân tâm thần phân liệt. Đối tượng và phương pháp: Sử dụng phương pháp mô tả cắt ngang, phân tích đặc điểm lâm sàng hành vi tự sát bằng phỏng vấn trực tiếp bệnh nhân tâm thần phân liệt và người nhà bệnh nhân được điều trị nội trú tại Viện Sức khỏe Tâm thân- Bệnh viện Bạch Mai. Kết quả: có 36 bệnh nhân có hành vi tự sát trong số 177 bệnh nhân chiếm tỷ lệ 20,3\%. Phân tích 36 bệnh nhân có hành vi tự sát chúng tôi thấy: bệnh nhân có ý tưởng tự sát $(100 \%)$, có toan tự sát $(66,7 \%)$, phổ biến ở nam giới, trẻ tuổi, tiền sử có hành vi tự sát. Bệnh nhân tự sát tại nhà $(66,6 \%$, cấp tính, không có sự chuẩn bị; phương thức tự sát đa dạng, bạo lực, có tỳ lệ cao bệnh nhân sử dụng nhiều phương thức gây hậu quả cở thể nặng nề. Kết luận: Bệnh tâm thần phân liệt có tỷ lệ cao có hành vi tự sát, phần lớn bệnh nhân tự sát tại nhà, không có sự chuẩn bị; phướng thức tự sát đa dạng, bạo lực gây hậu quả cơ thể nặng nề.

Tứ khóa: Bệnh tẩm thần phẩn liệt, hành vi tự sát

\footnotetext{
${ }^{1}$ Viện Sức khoẻ Tâm thần - Bệnh viện Bạch Mai,

${ }^{2}$ Trường Đại học Y Hà Nội

Chịu trách nhiệm chính: Phạm Công Huân

Email: huanphamcong150785@gmail.com

Ngày nhận bài: 6.4.2021

Ngày phản biện khoa học: 25.5.2021

Ngày duyệt bài: 7.6.2021
}

Phạm Công Huân', Dương Minh Tâm ${ }^{1,2}$

\section{SUMMARY}

\section{CLINICAL FEATURES OF SUICIDAL BEHAVIOR} AMONG INPATIENTS WITH SCHIZOPHRENIA

Objective: To describe clinical characteristics of suicidal behavior in patients with schizophrenia. Subjects and methods: Using a cross-sectional descriptive method, analyzing clinical characteristics of suicidal behavior by direct interviews with schizophrenic patients and their relatives are treated at the National Institute of Mental Health -Bachmai Hospital. Results: There were 36 patients with suicidal behavior out of 177 schizophrenic patients, accounted for 20,3\%. Analyzing 36 patients with suicidal behaviors, we found that: patients with suicidal ideation $(100 \%)$, attempted suicide $(66,7 \%)$, common among men, young people with a history of suicidal behavior. Most patients suddenly committed suicide at their houses $(66,6 \%)$; methods for suicide attempts were diverse and violent with a high percentage of patients performing multiple methods led to serious physical consequences. Conclusion: Patients with schizophrenia had a high rate of suicidal behavior; most people suddenly committed suicide at their houses with diverse and violent suicidal methods led to some serious physical consequences.

Keywords: Schizophrenia, suicidal behavior

\section{I. ĐẶT VẤN ĐỀ}

Bệnh tâm thần phân liệt là bệnh loạn thần nặng, chiếm tỷ lệ $0,3 \%-1 \%$ dân số. Biểu hiện 
lâm sàng của bệnh tâm thần phân liệt đa dạng với nhiêu nhóm triệu chứng khác nhau, nặng nề nhất là bệnh nhân có ý tưởng và hành vi tự sát gây thiệt hai về người, đau khổ về thể chất và tâm thần, ảnh hưởng tới kinh tế, hạnh phúc gia đình. Tỷ lệ chết do tự sát ở bệnh nhân tâm thần phân liệt là khoảng $10 \%$ [8]. Chết do tự sát là nguyên nhân chủ yếu làm giảm tuổi thọ ở bệnh nhân tâm thần phân liêt. Phát hiên sớm và can thiệp kịp thời các yếu tố nguy cơ tự sát ở bệnh nhẩn tầm thần phân liệt có vai trò quan trọng, góp phần làm giảm tỷ lệ tử vong, giảm gánh nặng bệnh tât cho cả bênh nhân, gia đình và xã hội.

Ở Việt Nam bệnh tâm thần phân liệt là chủ đề được nghiên cứu rộng rãi. Tuy nhiên, chưa có nhiêu nghiên cứu một cách có hệ thống lâm sàng hành vi tự sát ở bệnh nhân tâm thần phân liệt. Do vậy, chúng tôi tiến hành nghiên cứu đề tài này với mục tiêu: Mô tả đặc điểm lâm sàng hành vi tự sát ở bệnh nhân tâm thần phân liệt.

\section{II. ĐỐI TƯỢNG VÀ PHƯƠNG PHÁP NGHIÊN CứU}

Đối tượng nghiên cứu: 177 bệnh nhân, trong đó có 36 bệnh nhân có hành vi tự sát điêu trị nội trú tại Viện Sức khoẻ Tâm thần, thỏa mãn tiêu chuẩn chẩn đoán bệnh tâm thần phân liệt theo Bảng Phân loại bệnh Quốc tế về các rối loạn tâm thần và hành vi (ICD-10F) 1992 của Tổ chức $\mathrm{Y}$ tế Thế giới. Thời gian nghiên cứu: 07/2020 - 03/2021.

Phương pháp nghiên cứu: Nghiên cứu mô tả cắt ngang, phân tích đặc điểm lâm sàng hành vi tự sát thông qua phỏng vấn trực tiếp bệnh nhân và người nhà khi nằm viện. Xử lý số liệu bằng phần mềm SPSS 20.0.

III. KẾT QUẢ NGHIÊN CứU

1. Tỷ lệ bệnh nhân có hành vi tự sát sát

Bảng 3.1. Tỷ lệ bệnh nhân có hành vi tứ

\begin{tabular}{|c|c|c|}
\hline Các hành vi tự sát & Số lượng & Tỷ lệ \% \\
\hline Có & 36 & 20,3 \\
\hline Không & 141 & 79,7 \\
\hline Tống & $\mathbf{1 7 7}$ & $\mathbf{1 0 0}$ \\
\hline
\end{tabular}

Nhận xét: Tỷ lệ bệnh nhân có các hành vi tự sát là $20,3 \%$

Bảng 3.2 Tỷ lệ hành vi tự sát

\begin{tabular}{|c|c|c|c|}
\hline \multicolumn{2}{|c|}{ Các hành vi tự sát } & Số lượng & Tỷ lệ \% \\
\hline $\begin{array}{c}\text { Ŷ̀ tướng } \\
\text { tự sát }\end{array}$ & Cón & 36 & 100 \\
\hline \multirow{2}{*}{ Toan tự sát } & Có & 0 & 0 \\
\cline { 2 - 4 } & Không & 24 & 66,7 \\
\hline \multicolumn{2}{|c|}{ Tống } & 12 & 33,3 \\
\hline \multicolumn{2}{|c|}{} & $\mathbf{3 6}$ & $\mathbf{1 0 0}$ \\
\hline
\end{tabular}

Nhận xét: Trong số 36 bệnh nhân có hành vi tự sát, $100 \%$ bệnh nhân có ý tưởng tự sát;
66,7\% bệnh nhân có toan tự sát.

2. Tỷ lệ hành vi tự sát theo giới tính và nhóm tuổi

Bảng 3.3. Tỷ lê hành vi tự sát theo giới tính và nhóm tuối

\begin{tabular}{|c|c|c|c|}
\hline \multicolumn{2}{|c|}{$\begin{array}{c}\text { Giới tính và nhóm } \\
\text { tuổi }\end{array}$} & $\begin{array}{c}\text { Số } \\
\text { lượng }\end{array}$ & Tỷ lệ \% \\
\hline \multirow{2}{*}{ Giới tính } & Nam & 22 & $61,1 \%$ \\
\cline { 2 - 4 } & Nữ & 14 & $38,9 \%$ \\
\hline \multirow{3}{*}{ Nhóm tuổi } & $\leq 20$ & 5 & 14,0 \\
\cline { 2 - 4 } & $21-30$ & 17 & 47,2 \\
\cline { 2 - 4 } & $31-40$ & 6 & 16,6 \\
\cline { 2 - 4 } & $>40$ & 8 & 22,2 \\
\hline \multicolumn{2}{|c|}{ Tống } & $\mathbf{3 6}$ & $\mathbf{1 0 0}$ \\
\hline
\end{tabular}

Nhận xét: nam giới chiếm $61,1 \%$, nhóm tuối dưới 30 tuổi chiếm $61,2 \%$.

3. Tiền sử hành vi tưởng tự sát

Bảng 3.4. Tiền sử hành vi tự sát

\begin{tabular}{|c|c|c|c|}
\hline \multicolumn{2}{|c|}{$\begin{array}{c}\text { Tiền sử các hành vi } \\
\text { tự sát }\end{array}$} & Số lượng & $\begin{array}{l}\text { Tỷ lệ } \\
\text { \% }\end{array}$ \\
\hline \multirow{2}{*}{$\begin{array}{l}\text { Y tưởng tự } \\
\text { sát }\end{array}$} & Có & 16 & 44,4 \\
\hline & Không & 20 & 55,6 \\
\hline \multirow{2}{*}{$\begin{array}{c}\text { Toan tự } \\
\text { sát }\end{array}$} & Có & 11 & 30,6 \\
\hline & Không & 25 & 69,4 \\
\hline & 36 & 100 \\
\hline
\end{tabular}

Nhận xét: bệnh nhân có tiền sử có ý tưởng tự sát $(44,4 \%)$, tiên sử toan tự sát $(30,6 \%)$.

4. Phương thức và số lượng phương thức tự sát

Bảng 3.5. Phương thức và số lượng phương thức toan tự sát

\begin{tabular}{|c|c|c|c|}
\hline \multicolumn{2}{|c|}{$\begin{array}{c}\text { Phương thức và số lượng } \\
\text { toan tư sát }\end{array}$} & $\begin{array}{c}\text { Số } \\
\text { lượng }\end{array}$ & $\begin{array}{c}\text { Tỷ lệ } \\
\%\end{array}$ \\
\hline \multirow{7}{*}{$\begin{array}{l}\text { Phương } \\
\text { thức } \\
\text { toan tự } \\
\text { sát }\end{array}$} & Dùng dao đâm & 4 & 16,7 \\
\hline & Cắn lưỡi & 2 & 8,3 \\
\hline & Đập đầu vào tường & 3 & 12,5 \\
\hline & Nhảy lầu & 8 & 33,3 \\
\hline & Uống thuốc trừ sâu & 2 & 8,3 \\
\hline & Nhảy xuống sông & 2 & 8,3 \\
\hline & Khác & 3 & 12,5 \\
\hline \multirow{3}{*}{$\begin{array}{c}\text { Số } \\
\text { lượng }\end{array}$} & Một lần & 17 & 70,8 \\
\hline & Nhiều lần & 7 & 29,2 \\
\hline & Tống & 24 & 100 \\
\hline
\end{tabular}

Nhận xét: phương thức tự sát phố biến nhất là nhảy lầu $(33,3 \%)$, tiếp theo là dùng dao đâm $(16,7 \%)$, có $29,2 \% \%$ bệnh nhân thực hiện nhiều phương thức tự sát.

5. Địa điểm và sự chuẩn bị toan tự sát

Bảng 3.6. Địa điểm và sự chuẩn bị toan tự sát

\begin{tabular}{|c|c|c|c|}
\hline \multicolumn{2}{|c|}{$\begin{array}{c}\text { Địa điếm và sứ chuấn } \\
\text { bị toan tứ sát }\end{array}$} & $\begin{array}{c}\text { Số } \\
\text { lượng }\end{array}$ & $\begin{array}{c}\text { Tỷ lệ } \\
\text { \% }\end{array}$ \\
\hline \multirow{3}{*}{ Địa điểm } & Nhà riêng & 16 & 66,6 \\
\cline { 2 - 4 } & Bệnh viện & 4 & 16,7 \\
\cline { 2 - 4 } & Khác & 4 & 16,7 \\
\hline
\end{tabular}




\begin{tabular}{|c|c|c|c|}
\hline \multirow{2}{*}{ Sự chuẩn bị } & Không & 20 & 83,3 \\
\cline { 2 - 4 } & Có & 4 & 16,7 \\
\hline \multicolumn{2}{|c|}{ Tống } & $\mathbf{2 4}$ & $\mathbf{1 0 0}$ \\
\hline
\end{tabular}

Nhân xét: Bệnh nhân tự sát ở nhà $(66,6 \%)$; không có sự chuẩn bị $(83,3 \%)$

6. Hậu quả sau toan tự sát

Bảng 3.7. hậu quả sau toan tự sát

\begin{tabular}{|c|c|c|}
\hline $\begin{array}{c}\text { Hậu quả sau toan tự } \\
\text { sát }\end{array}$ & $\begin{array}{c}\text { Số } \\
\text { lượng }\end{array}$ & $\begin{array}{c}\text { Tỷ lệ } \\
\text { \%o }\end{array}$ \\
\hline Không ảnh hưởng & 11 & 45,8 \\
\hline Vết thương phân mêm & 6 & 25,0 \\
\hline Chấn thương sọ não & 1 & 4,2 \\
\hline Đa chấn thương & 1 & 4,2 \\
\hline Gãy chân, gãy xương & 2 & 8,4 \\
\hline Khác & 3 & 12,4 \\
\hline Tống & $\mathbf{2 4}$ & $\mathbf{1 0 0}$ \\
\hline
\end{tabular}

Nhânn xét: 25\% bệnh nhân bị vết thương phân mềm, 8,4\% bệnh nhân bị gãy chân, gãy xương, 4,2\% bệnh nhân bị đa chấn thương hoặc chấn thương sọ não.

\section{BÀN LUÂ̂N}

1. Tỷ lệ các hành vi tự sát. Theo bảng số liệu $(3.1,3.2)$ : bệnh nhân tâm thần phân liệt có $20,3 \%$ có hành vi tự sát, trong đó $100 \%$ bệnh nhân có ý tưởng tự sát, $66,7 \%$ bệnh nhân có toan tự sát.

Nghiên cứu khác, tỷ lệ hành vi tự sát ở bệnh nhân TTPL được ước tính cao gấp 10 lần so với quần thể dân số chung, tỷ lệ chết do tự sát cao, dao động từ $5-10 \%$, là nguyên nhân chính làm giảm tuổi thọ của bệnh nhân so với quần thể dân số chung [5]. Nhiều nghiên cứu có $60 \%$ bệnh nhân tâm thần phân liệt có ý tưởng tự sát, hoặc toan tự sát; một số nghiên cứu khác kết quả thấp hớn với khoảng $20 \%$ bệnh nhân có ý tưởng tự sát hoăc toan tự sát [2]. Nghiên cứu của Dong trên bệnh nhân tâm thần phân liệt ở Trung Quốc, có tỷ lệ ý tưởng tự sát và toan tự sát suốt đời là $25,8 \%$ và $14,6 \%$ tương ứng [3].

2. Tỷ lệ hành vi tự sát theo giới và nhóm tuổi. Trong các bệnh nhân có hành vi tự sát, nam giới chiếm tỷ lệ $61,1 \%$ cao hơn nữ giới với tỷ lệ tương ứng là 38,9\%.

Nghiên cứu khác cũng cho thãy nguy cơ có hành vi tự sát ở nam giới cao hơn 3-4 lần so với nữ giới. Jakhar và cộng sứ, có $60 \%$ nam giới có toan tự sát, tỷ lệ này ở nữ giới là $40 \%$ [6]. Phân tích gộp với cỡ mẫu trên 1000 bệnh nhân tâm thần phân liệt của Dong và cộng sự, tỷ lệ ý tưởng tự sát suốt đời ở nam và nữ lần lượt là $29,6 \%$ và $24,1 \%$; tỷ lệ toan tự sát suốt đời ở nam giới là $13 \%$, ở nữ giới là $13,8 \%$ [3]. Như vậy kết quả nghiên cứu của chúng tôi cũng tương đồng với kết quả nghiên cứu của nhiều tác giả khác.

Phần lớn bệnh nhân thuộc nhóm tuổi trẻ, 61,2\% bệnh nhân dưới 30 tuổi. Nhiều nghiên cứu chỉ ra rằng nguy cơ hành vi tự sát cao hơn ở người trẻ cả hai giới, bệnh nhân tâm thần phân liệt có hành vi tự sát có tuổi trẻ hơn bệnh nhân có hành vi tự sát ở các rối loạn tâm thần khác. Khi so sánh với nhiều nghiên cứu khác, kết quả của chúng tôi cũng tương đồng. Kết quả của Jakhar ở bệnh nhân tâm thần phân liệt có toan tự sát tuổi trung bình là khoảng 30 tuổi [6]. Nghiên cứu của Gill và cộng sự, ở những bệnh nhân tâm thần phân liệt có ý tưởng tự sát, nhóm tuổi chủ yếu là 13 đến 27 tuổi [4].

3. Tiền sử các hành vi tự sát. Nghiên cứu của chúng tôi có tỷ lệ cao bệnh nhân có tiền sử có ý tưởng hoặc hành vi tự sát. Nhiều nghiên cứu khác ở bệnh nhân tâm thần phân liệt có các hành vi tự sát thường có tiền sử có ý tưởng tự sát hoặc toan tự sát. Nghiên cứu của Jakhar ở bênh nhân có toan tự sát có $10 \%$ bênh nhân có tiền sử toan tự sát ít nhất 1 lần. Nghiên cứu của Aydin và cộng sự có $39,6 \%$ bệnh nhân có tiền sử toan tự sát, trong đó $60,4 \%$ bệnh nhân có toan tự sát 1 lần, 39,6\% bệnh nhân đã thực hiện toan tự sát nhiều hơn 1 lần [1].

4. Phương thức và số lượng phương thức tự sát. Bệnh nhân tâm thần phân liệt ở giai đoạn bệnh cấp tính, phần lớn hành vi tự sát do hoang tưởng hoặc ào giác xui khiến, dẫn đến phương thức thực hiện tự sát mang tính chất bạo lực, mãnh liệt, phổ biến dùng dao đâm, đập đầu vào tường, nhảy lầu. Ngoài ra, bệnh nhẩn tâm thần phân liệt có tỷ lệ cao sử dụng nhiều phương thức để tự sát. Nghiên cứu của Jakhar, phương thức tự sát rất đa dạng, phổ biến là sử dụng thuốc diệt côn trùng, dùng thuốc quá liều, treo cổ và nhảy lầu [6]. Nghiên cứu của Aydin, gần 40\% bệnh nhân toan tự sát 2 lần, có $25,3 \%$ bệnh nhân toan tự sát 3 lần; phương thức tự sát phổ biến là sử dụng thuốc uống $(53,8 \%)$, nhảy lâu $(15,4 \%)$, dùng dao đâm (14,3\%)[1]. Kết quả nghiên cứu của chúng tôi cũng tương đồng, bệnh nhân tâm thần phân liệt thường tự sát với phương thức bạo lực,đa dạng dẫn tới tỷ lệ tử vong cao.

5. Địa điểm và sự chuẩn bị toan tự sát. Phần lớn bệnh nhân thực hiện tự sát ở nhà riêng và không có sự chuẩn bị trước. Kết quả này cũng phù hợp với đặc điểm lâm sàng, bệnh thường khởi phát ở tuổi trẻ, không có công việc ổn định, chủ yếu ở nhà. Mặt khác, nguyên nhân toan tự sát phần lớn do ảo thanh xui khiến và hoang tưởng chi phối, những yếu tố này diễn biến rất 
nhanh, chi phối cảm xúc và hành vi của bênh nhân, khi xuất hiện ý tưởng hoặc hành vi tự sát bệnh nhân thực hiện mà không có sự chuẩn bị trước. Các nhà lâm sàng phải luôn luôn đánh giá nguy cơ tự sát ở bệnh nhân tâm thần phân liệt để có biện pháp can thiệp kịp thời.

6. Hậu quả của toan tự sát. Không có bệnh nhân nào tữ vong, tuy nhiên có nhiều bệnh nhân có hậu quả nặng nề như chấn thương sọ não, đa chấn thương, gãy chân, gãy xương. Kết quả này có thể được giải thích do bệnh nhân thường sử dunng những phương thức mang tính chất bao lực và nhiều phương thức tự sát. Nghiên cứu khác cũng cho kết quả bệnh nhân tâm thần phân liệt thực hiện toan tự sát thường có hậu quả nặng nề và có tỷ lệ tử vong cao. Nghiên cứu 113 bệnh nhân toan tự sát ở Nhật Bản, bệnh tâm thần phân liệt chiếm $32,7 \%$, phương thức tự sát là nhảy lầu với hậu quả trên cơ thể có nhiều phần bị tổn thương và nặng nề hơn so với toan tự sát ở các rối loạn tâm thần khác [7].

\section{KẾT LUÂNN}

Bệnh nhân tâm thần phân liệt có tỷ lệ cao có hành vi tự sát

Phần lớn bệnh nhân tự sát tại nhà và không có sự chuẩn bị trước; phương thức tự sát đa dạng, bạo lực, để lại hậu quả cơ thể nặng nề.

\section{TÀI LIÊU THAM KHẢO}

1. Aydın $M$, Ilhan BC, Tekdemir $R$, Cokünlü $Y$, Erbasan V, Altınbaş K. Suicide attempts and related factors in schizophrenia patients. Saudi Med J. 2019;40(5):475-482.

2. Castelein $S$, Liemburg EJ, de Lange JS, et al. Suicide in Recent Onset Psychosis Revisited: Significant Reduction of Suicide Rate over the Last Two Decades - A Replication Study of a Dutch Incidence Cohort. Voracek $M$, ed. PLoS ONE. 2015;10(6):e0129263.

3. Dong M, Wang SB, Wang F, et al. Suiciderelated behaviours in schizophrenia in China: a comprehensive meta-analysis. Epidemiol Psychiatr Sci. 2019;28(3):290-299.

4. Gill KE, Quintero JM, Poe SL, et al. Assessing Suicidal Ideation in Individuals at Clinical High Risk for Psychosis. Schizophrenia research. 2015; 165(0):152.

5. Hor $\mathbf{K}$, Taylor M. Suicide and schizophrenia: a systematic review of rates and risk factors. J Psychopharmacol. 2010;24 (4 supplement):81-90.

6. Jakhar K, Beniwal RP, Bhatia T, Deshpande SN. Self-harm and suicide attempts in Schizophrenia. Asian J Psychiatr. 2017;30:102-106.

7. Omi T, Ito $\mathbf{H}$, Riku $K$, et al. Possible factors influencing the duration of hospital stay in patients with psychiatric disorders attempting suicide by jumping. BMC Psychiatry. 2017;17(1):99.

8. Sher L, Kahn RS. Suicide in Schizophrenia: An Educational Overview. Medicina (Kaunas). 2019;55(7).

\section{KẾT QUẢ SỚM SAU ĐIỀU TRI NGOAI KHOA HUYẾT KHỐI TĨNH MACH SÂU CHI DƯỚI CẤP TÍNH}

\section{TÓM TẮT}

Mục tiêu: Đánh giá kết quả sớm sau can thiệp điều trị huyết khối tĩnh mạch sâu chi dưới cấp tính tai Bệnh viện Đại học Y Dược Thành phố Hồ Chí Minh. Phương pháp: Nghiên cứu tiến cứu, mô tả báo cáo loạt ca theo dõi dọc. Đối tượng nghiên cứu là bệnh nhân huyết khối tĩnh mach sầu chi dưới đoan châu đùi từ tháng 01/2016 đến tháng 12/2020. Bệnh nhân đước chia thành 2 nhóm: Nhóm điêu trị bằng phương pháp phẫu thuật mở; Nhóm được điều trị bằng can thiêp nội mach bơm tiêu sợi huyết tại chỗ. Kết quả: Tuổi trung bình của nhóm nghiên cứu là 47,3 $\pm 15,0$ tuổi. Độ tuổi thường gặp nhất là từ 40 - 60 tuổi chiếm tỉ lệ $39,1 \%$. Phần lớn bệnh nhân $(98,3 \%)$ có hình ảnh

\footnotetext{
${ }^{1}$ Bênh viẹn Đaii học Y Dượ TP.HCM

¿Đai hoc Y Dươ TP.HCM

Chịu trách nhiệm chính: Lê Phi Long

Email: long.lp@umc.edu.vn

Ngày nhận bài: 6.4.2021

Ngày phản biên khoa hoc: 24.5.2021

Ngày duyệt bài: 4.6.2021
}

Lê Phi Long ${ }^{1}$, Nguyễn Hoài Nam ${ }^{2}$

huyết khối hoàn toàn trên chụp cắt lớp vi tính. Hội chứng May-Thurner chiếm tỉ lệ 68,7\%. Không ghi nhận các biến chứng nặng: xuất huyết não và không có tử vong sau mổ. Tí lệ tái thông thất bại là $10,4 \% \%$,trong đó nhóm phấu thuật là $7,7 \%$ và nhóm can thiệp nội mạch là $14 \%$. Tî lệ cải thiện triệu chứng rõ rệt trên lâm sàng chiếm tỉ lể đa số là $47,8 \%$, cải thiện vừa chiếm $34,8 \%$. Biến chứng thường gặp nhất là chảy máu nhe sau mổ chiếm 12,3\%. Kết luân: Phương pháp can thiệp điều trị cho bệnh nhân bị huyết khối tĩnh mạch sầu chi dưới cấp tính có kết quả sớm tốt, cải thiện được triệu chứng sau can thiệp.

Tư khoá: huyết khối tĩnh mạch sâu, can thiệp nội mạch, phẫu thuật lấy huyết khối

\section{SUMMARY \\ EARLY OUTCOMES OF SURGICAL TREATMENT IN PATIENTS WITH ACUTE LOWER EXTREMITY DEEP VENOUS THOMBOSIS}

Objectives: To evaluate the early outcomes in the treatment of acute lower extremity deep vein thrombosis in the University Medical Center at Ho Chi Minh City. Method: A prospective descriptive cases 